OLIVEIRA, M.V., MOURA, M.S. e BARBOSA, F.C. Formulações peletizadas do fungo Monacrosporium sinense utilizadas no controle biológico de nematóides parasitos gastrintestinais de ovinos. PUBVET, Londrina, V. 5, N. 15, Ed. 162, Art. 1097, 2011.

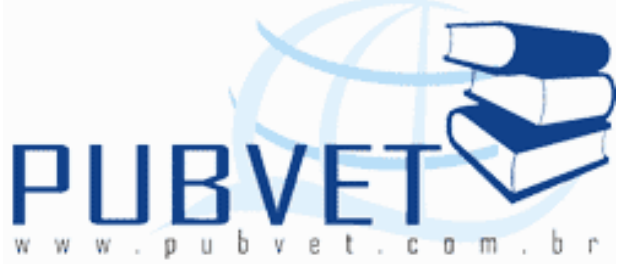

PUBVET, Publicações em Medicina Veterinária e Zootecnia.

\title{
Formulações peletizadas do fungo Monacrosporium sinense utilizadas no controle biológico de nematóides parasitos gastrintestinais de ovinos
}

Maiana Visoná de Oliveira ${ }^{1 *}$, Mariela Silva Moura ${ }^{1}$, Fernando Cristino Barbosa ${ }^{2}$

${ }^{1}$ Graduanda em Medicina Veterinária, Universidade Federal de Uberlândia. Uberlândia, MG.

${ }^{2}$ Docente da Faculdade de Medicina Veterinária, Universidade Federal de Uberlândia. Uberlândia, MG.

*Autor para correspondência: Rua Ceará, s/n, Bloco 2D, CEP 38400-902, Uberlândia, MG, Brasil. E-mail: maiana.visona@hotmail.com

\section{Resumo}

As perdas econômicas causadas pelas infecções por nematóides gastrointestinais de ovinos podem ser bastante significativas para os seus criadores. O desenvolvimento acelerado da resistência em helmintos gastrintestinais de ovinos e caprinos se tornou um dos maiores problemas para a ovinocultura e caprinocultura no Brasil. Esta atual resistência criada pelos parasitos aos anti-helmínticos tem incentivado a busca de métodos alternativos para o controle dos mesmos. Desta forma, o objetivo deste projeto foi fazer uma revisão bibliográfica sobre as formulações peletizadas do 
OLIVEIRA, M.V., MOURA, M.S. e BARBOSA, F.C. Formulações peletizadas do fungo Monacrosporium sinense utilizadas no controle biológico de nematóides parasitos gastrintestinais de ovinos. PUBVET, Londrina, V. 5, N. 15, Ed. 162, Art. 1097, 2011.

fungo Monacrosporium sinense levando em consideração a sua eficácia no controle da verminose ovina.

Palavras-chave: nematóides gastrointestinais, ovinos, controle, fungo.

\title{
Pelletized formulations Monacrosporium sinense fungus used in biological control of gastrointestinal nematodes of sheep
}

\begin{abstract}
The economic losses caused by gastrointestinal nematode infections of sheep can be quite significant for their creators. The fast development of resistance to gastrointestinal helminths of sheep and goats has become a major problem for sheep breeding and goat breeding in Brazil. This current resistance created by the parasites to anthelmintics has encouraged the search for alternative methods to control them. Thus, the objective of this project was to make a review about pelletized formulations of the fungus Monacrosporium sinense taking into account their effectiveness in controlling worms in sheep.
\end{abstract}

Keywords: gastrointestinal nematodes, sheep, control fungus.

\section{Introdução}

Análises de dados do IBGE mostram que a ovinocultura brasileira é uma atividade que vem se desenvolvendo na grande maioria das regiões brasileiras, expandindo-se para regiões onde, até então, não havia tradição nesse tipo de criação. Tais fatos apontam para um cenário em que a tendência da atividade é aumentar a sua importância e contribuição para a composição do produto interno bruto (PIB) do agronegócio brasileiro (MARTINS et al, 2006).

Segundo Vieira (2005), tanto a exploração de caprinos, quanto a de ovinos, vem crescendo por todo o país a mercê dos novos nichos de mercado que estão sendo conquistados e sedimentados. E neste processo, diversos problemas nos sistemas de produção constituem fatores limitantes para a produtividade dos rebanhos, e, por extensão, para a qualidade e a 
OLIVEIRA, M.V., MOURA, M.S. e BARBOSA, F.C. Formulações peletizadas do fungo Monacrosporium sinense utilizadas no controle biológico de nematóides parasitos gastrintestinais de ovinos. PUBVET, Londrina, V. 5, N. 15, Ed. 162, Art. 1097, 2011.

regularidade na oferta dos produtos deles derivados. Dentre estes problemas, questões ligadas ao manejo sanitário têm lugar expressivo nas perdas dos índices produtivos despertando em técnicos e produtores uma necessidade de controle e erradicação especialmente das endoparasitoses.

Dos parasitas de ovinos, as espécies mais comuns são Haemonchus contortus e Trichostrongylus colubriformis que normalmente vêm associadas a infecções por espécies de Cooperia spp, Oesophagostomum spp e Strongyloides papillosus (AMARANTE, 2004).

Formulações lançadas no mercado veterinário destinadas ao controle da verminose perdem a eficácia em poucos anos dentro da propriedade e a maioria dos criadores não tem acesso às informações técnicas atualizadas sobre o manejo parasitológico adequado do rebanho. Com isso, este desenvolvimento acelerado da resistência em helmintos gastrintestinais de ovinos e caprinos se tornou um dos maiores problemas para a ovinocaprinocultura no Brasil.

Esta resistência a anti-helmínticos pelos parasitos agravam as infecções causadas por eles e consequentemente agravam também as perdas econômicas que podem ser bastante significativas para os criadores, pois em geral, causam uma diminuição na taxa de crescimento do animal com progressiva perda de peso, redução na produção de lã, pobre desempenho reprodutivo, queda na produção de leite associada a baixos pesos dos cordeiros, gastos com medicamentos e alta mortalidade.

Esta enorme resistência dos parasitos frente à administração destes antihelmínticos disponíveis no mercado tem incentivado a busca de métodos alternativos para o controle dos mesmos e um deles é o controle biológico com uso de fungos nematófagos.

Estes fungos podem ser classificados como oportunistas e predadores (MOTA et al., 2003). E segundo Larsen (2002) somente os predadores são, experimentalmente, considerados os únicos capazes de atingir redução satisfatória de larvas no ambiente. 
OLIVEIRA, M.V., MOURA, M.S. e BARBOSA, F.C. Formulações peletizadas do fungo Monacrosporium sinense utilizadas no controle biológico de nematóides parasitos gastrintestinais de ovinos. PUBVET, Londrina, V. 5, N. 15, Ed. 162, Art. 1097, 2011.

Contudo, é importante ressaltar que não existe uma fórmula perfeita para controlar a verminose, mas sim ações preventivas de manejo que devem ser rigorosamente respeitadas. O conhecimento das características dos animais do rebanho, assim como o respeito ao bem-estar animal também são muito importantes, uma vez que o estresse causado por um manejo inadequado e tratamento abrutalhado pré-dispõem os animais não só à verminose, mas também a outras doenças (CHAGAS, 2005).

A ação dos fungos nematófagos sobre os nematóides gastrintestinais de ruminantes tem sido estudada de forma extensiva e com resultados promissores, entretanto poucos são os trabalhos realizados no controle biológico desses parasitos em ovinos a campo.

O objetivo da seguinte pesquisa é o estudo de formulações peletizadas do fungo predador de nematóides Monacrosporium sinense no controle de nematóides gastrintestinais de ovinos a campo.

\section{Revisão bibliográfica}

Embora os mecanismos de desenvolvimento de resistência parasitária aos anti-helmínticos ainda não estejam claros (GILLEARD, 2006), sabe-se que qualquer fármaco utilizado exerce uma pressão de seleção de genótipos resistentes na população. Assim, preconiza-se a associação de métodos alternativos e a utilização correta dos anti-helmínticos para controlar as infecções com a menor frequência de tratamentos possível e sem evitar por completo a exposição dos ruminantes aos parasitas, uma vez que este contato é necessário para o estímulo à resposta imune dos primeiros. Com os métodos alternativos de controle, são reduzidos, ainda, resíduos na carne e no leite e a agressão ambiental, que são conseqüências da aplicação dos quimioterápicos no rebanho (FLOATE, 2006).

Entre os métodos alternativos de controle está o de controle biológico, que consiste no uso de antagonistas naturais para restringir a um limiar subclínico e economicamente aceitável a ação de parasitas por meio da diminuição 
OLIVEIRA, M.V., MOURA, M.S. e BARBOSA, F.C. Formulações peletizadas do fungo Monacrosporium sinense utilizadas no controle biológico de nematóides parasitos gastrintestinais de ovinos. PUBVET, Londrina, V. 5, N. 15, Ed. 162, Art. 1097, 2011.

da fonte de infecção para os hospedeiros finais. Há vários antagonistas naturais de nematódeos descritos, entre eles: vírus, bactérias, amebas, fungos, nematódeos, vermes de vida livre, anelídeos e artrópodes (GRøNVOLD et al., 1996).

Waller (2002 e CEZAR; CATTO; BIANCHIN, 2008) destacam que a maioria da biomassa parasitária reside no ambiente onde está vulnerável a métodos bióticos e abióticos de controle, entre os quais, os antagonistas naturais.

Larsen (2002) destaca que, no combate aos nematódeos gastrintestinais, o antagonista natural é mais efetivo se aplicado no momento de maior concentração de larvas na pastagem.

O controle biológico é uma alternativa sustentável de combate às parasitoses, possibilita redução da freqüência de tratamentos com quimioterápicos (FONTENOT et al., 2003), reduzindo a pressão de seleção de parasitas resistentes, resíduos nos produtos de origem animal e danos ambientais.

Os fungos nematófagos (utilizados como uma forma de controle biológico) podem ser classificados como: oportunistas, parasitos de ovos; endoparasitos, capazes de infectar os nematódeos; e predadores (a maioria das espécies nematófagas), os quais fazem aprisionamento das larvas, seguido pela penetração das hifas e digestão dos conteúdos internos destas (MOTA et al., 2003). Fungos predadores são, experimentalmente, os únicos capazes de atingir redução satisfatória de larvas no ambiente (LARSEN, 2002) e sua ação efetiva é nos primeiros estágios larvais dos nematódeos (MOTA et al., 2003). Portanto, sua utilidade depende da capacidade de sobreviver à passagem pelo trato gastrintestinal dos animais, germinar nas fezes e capturar larvas infectantes (CEZAR; CATTO; BIANCHIN, 2008).

Os fungos predadores produzem grande quantidade de hifas que se modificam em estruturas especializadas (armadilhas) com a finalidade de capturar e fixar nematódeos (PADILHA, 1996). Essas estruturas podem ser 
OLIVEIRA, M.V., MOURA, M.S. e BARBOSA, F.C. Formulações peletizadas do fungo Monacrosporium sinense utilizadas no controle biológico de nematóides parasitos gastrintestinais de ovinos. PUBVET, Londrina, V. 5, N. 15, Ed. 162, Art. 1097, 2011.

aderentes ou não e serem produzidas espontaneamente ou em resposta a presença de nematódeos (PADILHA, 1996). Ainda de acordo com este autor, vários tipos de armadilhas podem ser desenvolvidos pelos fungos e nos que utilizam armadilhas aderentes, a substância adesiva pode cobrir toda a hifa ou apenas as estruturas especializadas e/ou as redes. As estruturas de captura não aderentes são os anéis constritores e os não constritores, os constritores têm ação ativa, geralmente têm três células e quando o nematódeo penetra no anel as células se expandem promovendo estrangulamento e os anéis não constritores são estruturas passivas. Assim, ao penetrarem nesses anéis os nemátodeos se enrolam e não conseguem sair (PADILHA, 1996).

Entre os predadores, os gêneros Arthrobotrys, Monacrosporium e Duddingtonia têm sido apontados como alternativas viáveis para o controle biológico das nematodíases em ruminantes e outros animais domésticos (FONTENOT et al., 2003; ARAÚjO et al., 2006), com destaque para a espécie Duddingtonia flagrans, com resultados positivos em diversos estudos conduzidos em várias regiões do mundo (LARSEN, 2002).

Quanto maior a motilidade dos nematóides, maior o estímulo ao fungo para a produção de armadilhas (ARAÚJO; MOTA; CAMPOS, 2004).

A formação delas era atribuída apenas às hifas. Mas de acordo com Dackman \& Nordbring-Hertz (1992), os esporos também podem produzir armadilhas. Eles mostraram que conídios de Arthrobotrys oligospora germinam diretamente em armadilhas aderentes quando adicionados em placas de ágar nas proximidades de fezes bovinas. Estas armadilhas são produzidas, possivelmente em resposta a substâncias estimulantes que se difundem das fezes. Segundo os autores, a possibilidade de formação de armadilhas a partir dos conídios é uma característica que permite ao fungo sobreviver à ação fungicida natural existente no meio ambiente.

Os estudos iniciais utilizando fungos nematófagos como controladores biológicos de parasitos gastrinstestinais de animais foram realizados no início do século XX, na França (ARAÚjO; MOTA; CAMPOS, 2004). 
OLIVEIRA, M.V., MOURA, M.S. e BARBOSA, F.C. Formulações peletizadas do fungo Monacrosporium sinense utilizadas no controle biológico de nematóides parasitos gastrintestinais de ovinos. PUBVET, Londrina, V. 5, N. 15, Ed. 162, Art. 1097, 2011.

No Brasil, estudos pioneiros demonstraram que Arthrobotrys spp e Monacrosporium ellipsosporum foram eficazes no controle de larvas de Haemonchus placei (ARAúJO et al., 1993).

Vários isolados do gênero Arthrobotrys foram testados sobre larvas infectantes de Haemonchus contortus de ovinos, onde se obteve redução significativa de larvas nas placas tratadas em comparação com as placas do grupo controle sem adição de fungo (MENDONZA DE GIVES et al., 1994).

Segundo Mota et al. (2000) citado por ARAÚJO; MOTA; CAMPOS, (2004), em um experimento de interação entre larvas infectantes de $H$. contortus, de caprinos e os fungos M. thaumasium e Arthrobotrys conoides, observou-se que os dois reduziram a população de larvas infectantes, porém a espécie $M$. thaumasium se mostrou mais eficiente.

Através de seis isolados dos fungos nematófagos (Monacrosporium thaumasium, Monacrosporium sinense, Monacrosporium appendiculatum, Arthrobotrys robusta, Arthrobotrys cladodes e Duddingtonia flagrans), Araújo et al. (2006), concluiram que em testes in vitro, os fungos foram capazes e eficientes em predar nematóides e todos os fungos testados são promissores para serem utilizados no controle biológico de Cooperia $s p$. e Oesophagostomum sp.

De acordo com Jobim (2006), administrando-se também o fungo Duddingtonia flagrans a bovinos criados a campo, houve uma diminuição da contagem de ovos por grama de fezes (OPG) e uma redução significativa de larvas na pastagem, demonstrando a importância biológica e eficácia deste fungo quando empregado em um controle integrado de nematódeos.

Também em bovinos, Araújo et al. (2004), avaliou a viabilidade de uma formulação do fungo Monacrosporium thaumasium associada com ivermectina no controle biológico de nematóides parasitos gastrintestinais e concluiu que admnistrando $20 \mathrm{~g}$ de pellets de $M$. thaumasium via oral, duas vezes por semana, num período de seis meses (que iniciou na estação chuvosa) tornam os tratamentos anti-helmínticos desnecessários. 
OLIVEIRA, M.V., MOURA, M.S. e BARBOSA, F.C. Formulações peletizadas do fungo Monacrosporium sinense utilizadas no controle biológico de nematóides parasitos gastrintestinais de ovinos. PUBVET, Londrina, V. 5, N. 15, Ed. 162, Art. 1097, 2011.

Em condições de laboratório, Araújo et al. (2004), demonstraram que o fungo M. sinense é efetivo no controle de larvas infectantes de Cooperia spp e Haemonchus.

Segundo Larsen (2002 e ARAÚJO; MOTA; CAMPOS, 2004), a administração de Arthrobotrys superba em grãos de cevada a bovinos infectados com nematóides parasitos gastrintetinais, reduziu o número de larvas infectantes recuperadas em coproculturas. Porém houve insucesso na administração de A. oligospora com grãos de cevada na alimentação de bovinos (GRØNVOLD et al., 1993).

Araújo et al. (2006), observaram a redução significativa no numero de larvas L3 de H. contortutus e Strongyloides papilosus, após tratamento dos animais como isolado fúngico de Duddingtotnia flagrans, demonstrando a viabilidade do fungo em predar após a passagem pelo trato gastrintestinal de caprinos.

Araújo, Mota e Campos (2004), avaliaram ação predadora do fungo Duddingtotnia flagrans sobre larvas de $H$. contortutus e Strongyloides papilosus após a passagem de clamidósporos, conídeos e micélios pelo trato gastrintestinal de caprinos, e observaram a redução significativa no numero de larvas recuperadas das culturas de fezes dos animais tratados quando comparado ao controle.

Araújo et al. (2007), também avaliou a viabilidade do fungo nematófago Monacrosporium thaumasium em caprinos criados a campo, no controle de larvas infectantes de nematóides gastrintestinais, no Semi-Árido cearense. 0 grupo de animais que recebeu o tratamento com o fungo uma vez por semana apresentou redução no número de ovos por grama de fezes, menor carga parasitária e maior ganho de peso, em relação aos animais de grupos em que não foi administrado o fungo, o que mostrou que o $M$. thaumasium é eficiente no controle de larvas infectantes nas pastagens e pode ser utilizado no controle e profilaxia de nematóides gastrintestinais de caprinos, no Semi-Árido cearense. 
OLIVEIRA, M.V., MOURA, M.S. e BARBOSA, F.C. Formulações peletizadas do fungo Monacrosporium sinense utilizadas no controle biológico de nematóides parasitos gastrintestinais de ovinos. PUBVET, Londrina, V. 5, N. 15, Ed. 162, Art. 1097, 2011.

Apesar de muitos autores afirmarem a eficácia destes fungos nematófagos, de acordo com Faedo et al. (1998) é preciso garantia da ausência de efeitos nocivos para possibilitar a comercialização destes fungos. Porém, estudos iniciais apontam que, nas concentrações utilizadas para controle biológico, estes não causam nenhum impacto ambiental significativo (LARSEN, 2002).

Ao redor das fezes de animais que receberam $D$. flagrans na dieta não há efeito negativo ao ambiente ou a invertebrados não-patogênicos (FAEDO et al., 2002).

Embora o emprego dos fungos nematófagos seja viável em sistemas comerciais manejados por fazendeiros (WALLER, 2002), não há formulações seguras e eficazes para comercialização do material fúngico e a forma de administração (em curtos intervalos por via oral) dificulta o manejo em sistemas de produção que não prevejam suplementação alimentar diária.

Os atuais métodos de controle biológico de nematódeos enfrentam barreiras de custo/benefício, aplicabilidade e segurança da obtenção de resultados (WALLER, 2002). São necessárias mais pesquisas para determinar os procedimentos mais adequados para que se obtenha êxito na sua utilização a campo.

\section{Referências}

AMARANTE, A. F. T. Controle da Verminose Garstrointestinal no Sistema de Produção de São Paulo, I Congresso Brasileiro de Especialidades em Medicina Veterinária. Paraná, 2004.

ARAÚJO, J. V. et al. Antagonistic effect of predacious Athrobotrys fungi on infective Haemonchus placei larvae. J. Helmintol., v.67, p.136-138, 1993.

ARAÚJO, J. V. et al. Efeito antagônico de fungos predadores dos gêneros Monacrosporium, Arthrobotrys e Duddingtonia sobre larvas infectantes de Cooperia sp. e Oesophagostomum sp. Arquivo Brasileiro de Medicina Veterinária e Zootecnia, v.58, n.3, p.373-380, 2006.

ARAÚjO, J. V. et al. Controle biológico de nematóides gastrintestinais de caprinos em clima semi-árido pelo fungo Monacrosporium thaumasium. Pesquisa agropecuária brasileira, v.42, n.8, p.1177-1181, 2007. 
OLIVEIRA, M.V., MOURA, M.S. e BARBOSA, F.C. Formulações peletizadas do fungo Monacrosporium sinense utilizadas no controle biológico de nematóides parasitos gastrintestinais de ovinos. PUBVET, Londrina, V. 5, N. 15, Ed. 162, Art. 1097, 2011.

ARAÚjO, J. V. et al. Controle de nematóides parasitos gastrintestinais de bovinos com pellets do fungo predador de nematóides Monacrosporium thaumasium. Ciência Rural, v.34, n.2, p.457-463, abr. 2004.

ARAÚJO, J. V. et al. Controle biológico de tricostrongilídeos (Nematoda: Trichostrongyloidea) gastrintestinais de bovinos pelo fungo Monacrosporium sinense. Arquivo Brasileiro de Medicina Veterinária e Zootecnia, v.56, n.4, p.467-47, ago. 2004.

ARAÚJO, J. V.; MOTA, M. A.; CAMPOS, A. K. Controle biológico de helmintos parasitos de animais por fungos nematófagos. Revista brasileira de Parasitologia Veterinária, Ouro Preto, v.13, 2004. Suplemento 1.

CHAGAS, A. C. S. Práticas de controle da verminose em ovinos e caprinos. Sobral: EMBRAPA-CNPC, 2005. 2 p. (EMBRAPA.CNPC. Comunicado Técnico, 63).

DACKMAN, C; NORDBRING-HERTZ, B. Conidial traps -a new survival structure of nematode trapping fungus Arthrobotrys oligospora. Mycol. Res., v.96, p.194- 198, 1992.

FAEDO, M. et al. Growth of the fungus Duddingtonia flagrans in soil surrounding feces deposited by cattle or sheep fed the fungus to control nematode parasites. Biological Control, v.23, p.64-70, 2002.

FAEDO, M. et al. The potential of nematophagous fungi to control the free-living stages of nematode parasites of sheep: Pasture plot study with Duddingtonia flagrans. Veterinary Parasitology, v.76, p.129-135, 1998.

FLOATE, K.D. Endectocide use in cattle and fecal residues: environmental effects in Canada. Canadian Journal of Veterinary Research, v.70, p.1-10, 2006.

FONTENOT, M.E. et al. Efficiency of feeding Duddingtonia flagrans chlamydospores to grazing ewes on reducing availability of parasitic nematode larvae on pasture. Veterinary Parasitology, v.118, p.203-213, 2003.

GILLEARD, J.S. Understanding anthelmintic resistance: the need for genomics and genetics. International Journal for Parasitology, v.36, p.1227-1239, 2006.

GRøNVOLD, J. et al. Biological control - Aspects of biological control with special reference to arthropods, protozoans and helminthes of domesticated animals. Veterinary Parasitology, v.64, p.47-64, 1996.

GRøNVOLD, J. et al. Biological control of nematode parasite in cattle with nematode trapping fungi: a survey of danish studies. Veterinary Parasitology, v. 48, p. 311-325, 1993.

JOBIM, M.B. O fungo Duddingtonia flagrans: controle biológico de nematódeos parasitas de bovinos à campo. 2006. 40f. Dissertação (Mestrado)- Programa de Pós Graduação em Medicina Veterinária, Universidade Federal de Santa Maria, Santa Maria, 2006.

LARSEN, M. Biological control in a global perspective - a review with emphasis on Duddingtonia flagrans. In: FAO. Animal Production and Health Division. Biological control of nematode parasites of small ruminants in Asia. Final proceedings... Rome, Italy: FAO, 2002. 104p. (FAO Animal Production and Health Paper). 
OLIVEIRA, M.V., MOURA, M.S. e BARBOSA, F.C. Formulações peletizadas do fungo Monacrosporium sinense utilizadas no controle biológico de nematóides parasitos gastrintestinais de ovinos. PUBVET, Londrina, V. 5, N. 15, Ed. 162, Art. 1097, 2011.

MARTINS, E.C.; GARAGORRY, F.L.; FILHO, H.C. Evolução da ovinocultura brasileira no período de 1975 a 2003. Sobral: EMBRAPA-CNPC, 2006. 4 p. (EMBRAPA.CNPC. Comunicado Técnico, 67).

MENDONZA DE GIVES et al. In vitro trapping capability of Arthrobotrys spp on infective larvae of Haemonchus contortus and Nacobbus aberrans. J. Helmintol., v. 68, p. 223-229, 1994.

MOTA, M.A. et al. Controle biológico de helmintos parasitos de animais: estágio atual e perspectivas futuras. Pesquisa Veterinária Brasileira, v.23, n.3, p.93-100, 2003.

PADILHA, T. Atividade de fungos nematófagos nos estágios pré-parasitários de nematódeos Trichostrongilídeos. Ciência Rural, Santa Maria, v.26, n.2, p.333-341,1996.

VIEIRA, L. S. Endoparasitoses Gastrintestinais em Caprinos e Ovinos. Sobral: EMBRAPACNPC, 2005. 32 p.- (Série Documentos / Embrapa Caprinos, ISSN 1676-7659 ; 58).

WALLER, P.J. Global perspectives on nematode parasite control in ruminant livestock: the need to adopt alternatives to chemotherapy, with emphasis on biological control. In: FAO. Animal Production and Health Division. Biological control of nematode parasites of small ruminants in Asia. Final proceedings... Rome, Italy: FAO, 2002. 104p. (FAO Animal Production and Health Paper). 